\title{
L'afropéanisme dans Tels des astres éteints de Léonora Miano : une scription rhématique de la transmigration des identités
}

\author{
Afropeanism in Léonora Miano's "Tels des astres éteints": \\ a rhematic scription of identities transmigration
}

\author{
Arsène Blé Kain \\ Université Alassane Ouattara, Côte d'Ivoire
}

Résumé: L'afropéanisme, cette notion popularisée dans l'espace francophone par l'écrivaine camerounaise Léonora Miano, concerne les Noirs ayant l'une des nationalités européennes et possédant une culture à la fois africaine et européenne, voire américaine. Cette identité de l'entredeux, paradigmatique de la transmigration des identités, est matérialisée dans Tels des astres éteints par le brassage linguistique perceptible dans l'expression des personnages et par leurs goûts musicaux hybrides qui assemblent des airs africains, européens et américains. Leurs dénominations hétérogènes les inscrivent, par ailleurs, dans cette logique de métissage culturel puisqu'ils ne portent que des prénoms qui ressortissent de sphères culturelles autres que celles dont ils sont originaires. Par ce jeu d'écriture, Tels des astres éteints de Léonora Miano apparaît finalement comme une scription rhématique de la transmigration des identités.

Mots-clés : afropéanisme, transmigration des identités, brassage linguistique, goûts musicaux hybrides, dénominations hétérogènes.

\begin{abstract}
The afropeanism, notion popularized in the Francophone space by the Cameroonian writer Leonora Miano, relates to European national Black people having both an African and European and even American culture. This inter-identity paradigmatic of identities transmigration is materialized in Tels des astres éteints by the linguistic melting pot, characteristic of individuals' expressions, and by their hybrid tastes in music, a mix of African, European and American tunes. Furthermore, their heterogeneous names are part of this mingling of cultures logic since having first names from cultural spheres other than their origins. In the end, Tels des astres éteints appears like a rhematic scription of identities transmigration.
\end{abstract}

Keywords: afropeanism, identities transmigration, linguistic melting pot, hybrid tastes in music, heterogeneous names.

\section{Introduction}

Les productions littéraires africaines questionnent aujourd'hui le lecteur au sujet de leur appellation générique, qui est ambivalente. Initialement définies par le qualificatif globalisant de littérature africaine ou par celvi englobant de littérature négro-africaine, ces œuvres, eu égard aux orientations spécifiques prises selon les 
sociétés nationales dont elles sont issues, ont finalement conduit les exégètes à un débat sur la question des littératures nationales en Afrique noire.

Avec les nombreuses réflexions en sciences humaines, sociales et politiques sur la notion d'u identité " et la reconnaissance du caractère évolutif, et même évolutionniste, du processus d'identification en tant que construction permanente et dynamique, les auteurs africains actuels semblent se défaire de la catégorisation littéraire guidée par le critère géographique ou celui de la couleur de la peau, pour faire désormais leurs les concepts identitaires nouveaux que sont la diversalité, l'antillanité, la créolité, l'afropolitanisme ou encore l'afropéanisme. Le dernier nommé constitue, du reste, le motif fondamental des écrits de la Camerounaise Léonora Miano.

Dans Tels des astres éteints (2008), elle offre les portraits et raconte les tranches de vie de personnages noirs, africains ou d'origine africaine, qui vivent dorénavant en France et qu'elle qualifie d'Afropéens. Quelle est la nature réelle de l'identité de ces individus qu'elle présente dans le pays qui les accueille aujourd'hui ? Comment parvient-elle à renégocier les rapports d'altérité et d'identité dans la construction de leur identité afropéenne? Quelles postures idéologiques sous-tendent l'afropéanisme tel que transcrit dans son œuvre?

Une lecture socio-pragmatique du texte précité permettra, suivant l'appréhension de ce concept par Miano, de décrypter l'une des optiques identitaires dans laquelle s'inscrivent, de nos jours, les écrivains africains. La présente étude se propose ainsi d'examiner de prime abord l'afropéanisme comme une identité émergente ascendante avant de révéler ensuite comment, chez Miano, il constitue une véritable écriture des identités transmigrantes.

\section{L'afropéanisme, une identité émergente ascendante}

La naissance du terme "afropéanisme " remonterait au groupe musical belge d'origine zaïroise Zap Mama et surtout à son album sorti en 1993, intitulé Adventures in Afropea. Ce vocable ressurgit, une décennie plus tard, dans un article du New York Times traitant de deux chanteuses françaises', Les Nubians, présentées comme un groupe représentatif de la "scène musicale afropéenne qui fleurit en France " (Faure 2015). Depuis lors, en Angleterre, quelques jeunes animent un journal dénommé Afropean - Adventures in Black Europe. Dans l'espace francophone, le mot se popularise aussi bien avec les conférences de la Camerounaise Léonora Miano qu'à travers ses œuvres romanesques.

Pour évoquer l'afropéanisme, Léonora Miano parle d'identités frontalières en affirmant qu' "être afropéen, de nos jours, c'est habiter la frontière " (Miano, 2012 : 87). La frontière, pour elle, est un espace cicatriciel, cicatrice non pas en termes de plaie, mais plutôt en tant que nouvelle ligne de vie. Loin de la limite, de la démarcation, du lieu de séparation et de repli sur soi, la frontière se présente ici comme un lieu de contact, un espace de rencontre qui unit les peuples, métisse les hommes, donne naissance à de nouvelles hybridités. La frontière est l'endroit où les mondes se touchent, inlassablement. C'est le lieu de l'oscillation constante d'un espace à l'autre, d'une sensibilité à l'autre, d'une vision du monde à l'autre. C'est là

\footnotetext{
1 Deux sœurs, Hélène et Célia Faussart, de père français et de mère camerounaise, ayant vécu au Tchad.
} 
où les langues se mêlent, s'imprégnant naturellement les unes des autres, pour produire la représentation d'un univers composite, hybride. " La frontière, dira-t-elle, évoque la relation. La frontière dit que les peuples se sont rencontrés, quelquefois dans la violence, la haine, le mépris, et qu'en dépit de cela, ils ont enfanté du sens $॥$ (Miano, 2012: 89), ce sens qui fait que le monde est, aujourd'hui, hybride.

Habiter la frontière, c'est donc habiter sa propre hybridité. C'est ce qu'elle essaie, du reste, de faire comprendre quand elle déclare :

Ma multi appartenance est porteuse de sens. Elle rappelle, à ceux qui croient en la fixité des choses, des identités notamment, que non seulement la plante ne se réduit pas à ses racines, mais que ces dernières peuvent être rempotées, s'épanouir dans un nouveau sol. Une plante peut également croiser ses racines avec celles d'une autre, et engendrer un nouvel être vivant. Ainsi en est-il des Afropéens, ces Français d'ascendance subsaharienne ou caribéenne, que l'on englobe abusivement sous le terme de "communauté noire " (Miano, 2012: 4ème p. de couverture).

Le qualificatif " afropéen » renvoie au fait d'être noir et d'être né en Europe. Être afropéen signifie plus précisément être noir, mais être né en Europe ou y avoir grandi. II s'agit d'une appartenance culturelle multiple. Soumahoro Maboula' le définit plus exactement comme étant « la condition particulière des Noirs européens qui vivent une expérience racialisée, dans un espace à majorité blanc " (Faure, 2015). Pour Daniel Larangé (2014 : 59), l'Afropéa est une identité en émergence qui se reconnaît dans une appartenance du Noir à l'Europe II soustrait ainsi le Noir de l'imaginaire dans lequel sa couleur renvoie à l'Afrique tout comme sa présence en Occident procède de l'immigration.

L'afropéanisme apparaît donc comme une identité nouvelle et collective concernant les descendants africains vivant en Europe. II est une exhortation des Afro-descendants européens à s'inventer, à se dire, à se créer soi-même. C'est ce cheminement intérieur que Miano décrit quand elle affirme que :

c'est cette maturation progressive de leur parcours identitaire que j'appelle Afropéa, un lieu immatériel intérieur, où les traditions, les mémoires, les cultures dont ils sont dépositaires, s'épousent, chacune ayant la même valeur (Miano, 2012:86).

Cette redéfinition de l'identité des Noirs européens justifie, par ailleurs, sa révolte contre une certaine opinion qui, en France, définit l'identité nationale comme le fait d'être natif du pays, identifiant ipso facto tous les autres Français issus de l'immigration ou de descendance immigrée à des étrangers. Elle voit en cette conception discriminatoire de l'identité nationale une grave méprise dès l'instant où des Noirs ayant migré en France ont acquis des habitus français et ne sont plus des Africains authentiques, n'ayant même plus de rapports réels avec leur continent d'origine ; d'autres encore, bien que descendants de parents immigrés, ne connaissent pas l'Afrique et n'ont que la France comme repère géographique et culturel. Cette situation hors des frontières conçues par les pratiques sociales occidentales qui induisent une dichotomie Europe/Afrique, Blancs/Noirs, fait d'eux des hybrides, puisqu'ils appartiennent apparemment aux deux groupes.

\footnotetext{
2 Maître de conférences à l'Université de Tours, en France, et spécialiste des diasporas africaines.
} 
C'est d'ailleurs en réponse à cette image de la France vue sous le prisme racialisé, à cette image d'une France blanche qui persiste dans les mentalités, que l'Afropéenne franco-ivoirienne Éva Doumbia organise du 28 au 30 octobre 2016, à Marseille, le premier festival Massilia Afropéa pour mettre en avant les esthétiques afropéennes. Dépassant le questionnement sur l'existence d'une culture afropéenne, elle proclame, de fait, cette identité désormais émergente et ascendante en France.

Lors de ce festival cependant, des artistes comme la romancière guadeloupéenne Maryse Condé, l'écrivain-journaliste malgache Jean-Luc Raharimanana, la slameuse camerounaise Silex, ont exprimé, à travers un débat intitulé "L'appartenance afropéenne ", leurs doutes et leurs réticences quant à l'emploi du terme Afropéa (Heluin, 01/11/2016). Pour Maryse Condé, ce mot est très réducteur : elle revendique sa pluralité et refuse d'être limitée à deux cultures puisqu'ayant d'abord grandi en Guadeloupe et ensuite vécu en France, elle ne sait qui elle est, et refuse d'être qualifiée d'Afropéenne. Le Malgache Jean-Luc Raharimanana a, quant à lui, affirmé comprendre l'afropéanité, tout en regrettant qu'il soit nécessaire de poser des définitions pour dire ce qu'on est. Pour lui, il est évident qu'il existe entre toutes les cultures des attirances et des points de rencontre. Née au Cameroun et installée en France depuis deux ans, la slameuse Silex reconnaît certes son intérêt pour les écrits de Léonora Miano, mais elle affirme son malaise par rapport au terme « afropéen ».

Sans leur répondre directement, Éva Doumbia essaie de clarifier l'identité afropéenne. Loin de considérer l'afropéanisme comme clos sur lui-même, Éva Doumbia démontre, tout au long du festival, l'ouverture de cette identité ou " territoire intérieur $\gg$ à diverses influences et évolutions; elle place l'afropéanisme dans le sillage de l'expérience afro-américaine (Héluin, 12/12/2016). Pour elle, l'identité afropéenne ne se limite pas à un entre-deux-continents, puisqu'elle demeure ouverte au monde, avec des références culturelles multiples, américaines entre autres.

Les différentes positions des uns et des autres par rapport à la notion d'afropéa dans un monde globalisé prouvent qu'il existe bel et bien une différence de culture entre les Noirs d'Afrique et ceux des différentes diasporas. L'affirmation d'une essence intemporelle et immuable du Noir, soutenue par Aimé Césaire et fort bien résumée dans la formule de Frantz Fanon : "Où qu'il aille, un nègre demeure un nègre ॥ (Fanon, 1952 : 160), est ainsi décrédibilisée. Depuis longtemps déjà, René Depestre s'oppose à une telle thèse. Pour lui, il n'y a pas une culture noire unique et identique à elle-même toujours et partout, de même qu'il n'y a pas non plus une littérature noire dont les thèmes et les modes d'expression seraient les mêmes dans toutes les communautés noires; car toute culture et toute littérature demeurent déterminées, non seulement par les éléments hérités du passé, mais aussi par les contingences historiques et les influences du milieu (Depestre, 1965 : 142-152). Cet ancrage dans le passé, vécu la plupart du temps à travers une relation imaginaire à l'Afrique, et le fait de s'imprégner au quotidien de la vie européenne, voire américaine, font, de nos jours, de l'Afropéen un être hybride.

Décrivant un processus similaire dans son essai Les identités meurtrières (1998), Amin Maalouf prend le cas d'un homme né en Allemagne de parents turcs : " Aux 
yeux de sa société d'adoption, il n'est pas allemand; aux yeux de sa société d'origine, il n'est plus vraiment turc " (Maalouf, 1998 : 9-10). Cet état de quasiapatridie soulève plusieurs questions : pourquoi de telles personnes ne peuvent-elles pas assumer leurs appartenances multiples? Pourquoi sont-elles constamment mises en demeure de choisir l'une ou l'autre ? L'auteur répond de façon péremptoire :

À cause de ces habitudes de pensée et d'expression si ancrées en nous tous, à cause de cette conception étroite, exclusive, bigote, simpliste qui réduit l'identité entière à une seule appartenance (Maalouf, 1998 : 11).

II ne s'agit donc plus assurément de chercher à valoriser l'une ou l'autre des composantes de cette identité, mais de reconnaître la situation privilégiée dans laquelle l'on se trouve quand on a la possibilité de choisir le meilleur de chaque culture. Cette appartenance plurivoque, que l'écrivain franco-libanais Amin Maalouf qualifie d'identités meurtrières, concerne :

des êtres portant en eux des appartenances qui, aujourd'hui, s'affrontent violemment; des êtres frontaliers, en quelque sorte, traversés par des lignes de fracture ethniques, religieuses ou autres. En raison même de cette situation (...) «privilégiée », ils ont un rôle à jover pour tisser des liens, dissiper des malentendus, raisonner les uns, tempérer les autres, aplanir, raccommoder... Ils ont pour vocation d'être des traits d'union, des passerelles, des médiateurs entre les diverses communautés, les diverses cultures (Maalouf, $1998: 11$ ).

Sylvie Chalaye, pour sa part, préfère l'idée du marcottage, perçu sous la forme imagée

d'un grand arbre d'Afrique dont les branches ont ployé vers l'Europe et les Amériques et où elles ont pris à leur tour racines et donné naissance à d'autres arbres et d'autres espèces aux fruits inouïs (Chalaye, $2014: 21$ ).

Pour Chalaye, en effet,

la culture française de 2015 ne peut se définir sur les contours de ce qui faisait la culture française en 1815 ou 1915. Elle a absorbé l'histoire coloniale, les guerres de 14-18 et 39-45, mais aussi de nouveaux courants de pensée, de nouveaux courants esthétiques, l'ère des télécommunications, la mondialisation, la révolution internet...et elle s'est nourrie de toutes les migrations, anciennes et récentes qui ont traversé l'hexagone (Chalaye, $2014: 17)$.

Si le terme "afropéen» semble cependant beaucoup plus concerner, aujourd'hui, les Noirs d'Europe, en général, et plus particulièrement ceux de France, c'est parce que, aux dires de Thomas Dominic, "L'identité européenne est définie aujourd'hui, avant tout, négativement contre la pression migratoire " (Dominic, 2014 : 100). En témoigne les façons de nommer les Afro-descendants : alors qu'en France l'on parle d' "immigrés de seconde génération», aux États-Unis, ils sont qualifiés d' "Américains de première génération », renversant ainsi le regard sur une même situation.

Parler d'Afropéens serait donc, comme le pense Pauline Vermeren, une tentative de définition, donc de nomination et de reconnaissance de ceux qui, malgré leur naissance ou leur résidence en France ou en Europe, sont encore qualifiés de 
"Noirs» dans l'espace hexagonal, voire européen, afin de traduire leur identité fusionnant deux territoires - Afrique et Europe (Vermeren, 2014 : 75).

Ce positionnement dans l'entre-deux, Léonora Miano le corrobore en ces termes: « J'écris dans l'écho des cultures qui m'habitent: africaine, européenne, afro-américaine, caribéenne " (Makhlouf, 2017). Cette expérience afropéenne du «ni africain ni américain ni européen », mais "hommes de tous les continents $\|^{3}$ qu'elle décrit si bien est paradigmatique de ses écrits. Tels des astres éteints s'y abreuve abondamment, démontrant assurément que, chez Léonora Miano, l'afropéanisme apparaît comme une écriture des identités transmigrantes.

\section{L'afropéanisme de Léonora Miano : une écriture des identités transmigrantes}

Les personnages de Léonora Miano sont presque tous issus de la diaspora africaine. Ils vivent en France et sont des immigrés ou des descendants d'immigrés. Ils partagent, à ce titre, la même préoccupation en ce qui concerne la définition ou la redéfinition de leur identité. Miano les qualifie d'Afropéens du fait qu'ils ne sont ni africains ni européens, ou, du moins, qu'ils sont à la fois africains et européens. Ces personnages qui, par leur origine, assignent à l'Afrique le rang d'espace-repère garantissant leur équilibre moral et émotionnel, "possèdent officiellement une identité reconnue française qu'ils vivent dans une nation française selon leur mode d'être " (Tang, 2014: 67). Cette situation d'entre-deux laisse transparaître une certaine transmigration des identités dans les écrits de Léonora Miano.

Du latin transmigrationem procédant du verbe transmigrare, lui-même composé de trans- qui veut dire "au-delà» et de migrare qui signifie "aller», la " transmigration » renvoie à deux réalités. Elle se rapporte, dans un premier temps, à l'action d'un peuple, d'une nation, d'une troupe d'hommes qui abandonnent leur territoire pour aller en habiter un autre : c'est dans ce sens que les Écritures saintes parlent de «la transmigration de Babylone » pour désigner le transport du peuple juif à Babylone et le séjour qu'il y fit. Le terme se retrouve aussi dans l'expression " transmigration des âmes », faisant référence à l'opinion des Pythagoriciens et, par extension, à la croyance, après la mort, d'un possible passage de l'âme depuis un corps vers un autre support, qu'il soit humain, animal ou matériel. Dans tous les cas, comme l'affirme l'écrivain spiritualiste français Bernard Baudoin,

il est question d'un passage, d'un transfert du principe vivant d'un " hôte matériel» vers un autre, afin de lui impulser une certaine dynamique, différente de celle qui était la sienne auparavant (Baudoin, 2014 : 22).

Ramenée à la présente étude, la transmigration renvoie également à l'idée de passage, de transfert. Parler de transmigration des identités revient effectivement à montrer comment, par le jeu de l'écriture et, particulièrement, par la médiation des personnages qui s'y retrouvent, Léonora Miano laisse découvrir ses textes comme une constellation d'identités en mouvement. Cette identité plurielle que l'auteure désigne sous l'appellation néologique d'afropéa fait de Tels des astres éteints une scription rhématique de la transmigration des identités, tant par le caractère hybride de la culture dans laquelle évolvent les personnages que par l'hétérogénéité du système de désignation anthroponymique.

\footnotetext{
3 Titre d'un recueil de poèmes de l'écrivain ivoirien Bernard B. Dadié (Hommes de tous les continents, Paris, Présence africaine, 1967).
} 
L'hybridité culturelle des personnages de Léonora Miano transparaît avec netteté dans le brassage linguistique et musical qui participe de leur identité. La cohabitation forcée en eux de cultures diverses les installe, de fait, dans une situation de diglossie, voire de polyglossie. Ce multilinguisme est évidemment reflété dans leurs propos en français aussi bien à travers des emprunts que par des calques, des alternances et des mélanges codiques.

Pour Dubois et alii,

il y a emprunt quand un parler A utilise et finit par intégrer une unité ou un trait linguistique qui existait précédemment dans un parler B (dit langue source) et que A ne possédait pas; l'unité ou le trait emprunté sont euxmêmes qualifiés d'emprunt (Dubois et alii, 2001 : 177).

Les emprunts que contient Tels des astres éteints ressortissent des langues africaines, de l'anglais, du franglais (pidgin anglais du Cameroun), du créole et du français des quartiers populaires de France. Ces emprunts indiquent les différentes cultures dans lesquelles baignent les personnages principaux. L'emprunt du terme "Mbengué " à la langue douala du Cameroun pour signifier "I'Occident" et celui de «bissap », moł wolof du Sénégal désignant une variété d'hibiscus qui produit un jus comestible, révèlent, par exemple, les origines africaines des personnages afropéens que sont Amok et Shrapnel. Le recours à l'anglais à travers les mots "fitness" (gymnique), "super freak" (fille perverse), "motherland" (la terre mère, l'Afrique), et au pidgin anglais "sista" (déformation de l'anglais sister), "simol massa " (déformation de l'anglais small master), "boogies" (une fête), attestent la double colonisation qu'a connue le Cameroun d'où sont précisément originaires Amok et Shrapnel. Un terme créole guyanais comme " bagage » pour dire " chose " explicite la part identitaire de la Caribéenne Amandla. Le commerce de tous ces personnages avec les milieux populaires français justifie, in fine, le français populaire que l'on retrouve dans des mots comme "tchiper»" (bruit strident émis en appliquant la langue sur l'arrière des dents pour signifier le mépris ou la raillerie), " ambianceurs » (noceurs).

À côté de ces emprunts, figurent aussi des calques. Pour le linguiste camerounais Edmond Biloa, un calque est une forme d'emprunt lexical particulier qui consiste à transposer les unités lexicales d'une langue dans les structures d'une autre langue (calque syntaxique) ou à traduire littéralement en les transposant dans une langue des constructions lexico-sémantiques empruntées à une autre langue - calque sémantique (Biloa, 2007 : 267). Tels des astres éteints recourt ainsi à différents calques sémantiques à travers de nombreuses tournures détournées de leur sens originel au Cameroun. II en est ainsi des expressions "sans confiance " (nom donné à des tongs en plastique très bon marché), "pain chargé " (terme familier employé pour dire sandwich) et des mots tels que "poteau» (dénomination commune des "librairies" de plein air, généralement constituées de vieux livres posés à même le sol, sous des poteaux électriques) et "soviller" (en langage familier du Cameroun, c'est faire honte).

Un autre fait de langue certifiant l'hybridité culturelle des personnages afropéens se décèle également à travers l'alternance et le mélange codique. Lovis-Jean Calvet considère le mélange des codes comme le passage d'un point du discours à l'autre quand ce passage se produit à l'intérieur d'une phrase, et l'alternance 
comme le passage d'un point du discours à l'autre quand ce passage se fait d'une phrase à la suivante ou d'un locuteur à l'autre (Calvet, 1993:29). Ce procédé est visible chez Léonora Miano à travers le mélange du français et du camfranglais ${ }^{4}$ : " Gars, tu n'es même pas back au lage avec un costume Armani ou Dior? Tu n'as pas les dos, ou bien? II. Back au lage, en camfranglais, c'est rentrer au village. Le mot lage se prononce ledj, comme dans l'anglais village. Les dos, c'est l'argent: il s'agit d'un abrégé de dollars.

En parsemant son texte français d'anglicismes, de créolismes et d'africanismes, Léonora Miano signale la multi-appartenance identitaire de ses personnages. II s'agit pour elle, aux dires de Sophia Mizouni, « de bouger en dehors des frontières raciales préalablement imposées afin de reconstruire ou de ré-imaginer son identité » (Mizouni, 2014: 305). Cette réinvention identitaire qui s'effectue par la déconstruction de la langue française et sa reconstruction à travers un langage nouveau "créolisé » afin d'effacer les différences polaires entre Noirs et Blancs est également perceptible dans le brassage musical caractéristique du goût musical des personnages. L'intérêt porté à ce tissage musical se fixera surtout, dans la présente étude, sur les principaux personnages (Amok, Shrapnel et Amandla) dont les parcours structurent le roman.

Amok est un inconditionnel de la soul music, une musique qui a ses racines dans le gospel traditionnel afro-américain, dans le rythm and blues et dans l'hybridation de leurs styles respectifs séculaires et religieux. II aime à écouter les chanteurs représentatifs de cette musique que sont Curtis Mayfield et Teddy Pendergrass (351). Quant à Shrapnel, il a également un faible pour la soul music, mais en plus, il est un fervent adepte du hip hop, du rap et du funk, autant de genres musicaux influencés par le reggae, le blues et le jazz. II a en horreur les musiques africaines (le coupé décalé, la musique des griots) ou les airs afro-caribéens que sont la salsa, le zouk, le reggae (214-215). Amandla, la Caribéenne, apprécie plutôt les musiques africaines et le reggae. Elle n'éprouve aucune attirance pour le zouk ni pour la salsa, qui sont pourtant originaires de sa Caraïbe natale, a fortiori pour la soul music dont est féru son amant Amok (298).

La musique participe assurément de la (re)construction de l'identité des personnages dans Tels des astres éteints. Elle constitue, du reste, le principe structurel de l'écriture romanesque de Miano dont le roman est conçu comme un air de musique avec le choix d'une terminologie musicale (intro et outro pour désigner respectivement le prologue et l'épilogue du roman) et de titres de chansons de jazz qui forment les titres des sections. Cette technique d'écriture basée sur des expressions musicales aux influences à la fois occidentale, africaine et américaine, qui constituent les goûts musicaux des personnages, permet finalement de comprendre l'hybridation culturelle qui marque le système de désignation de ces derniers.

Pour Brussosa, « même si dans Tels des astres éteints la création anthroponymique semble s'enraciner dans une longue tradition africaine, elle ne le fait que partiellement» (Brussosa, 2013: 144). Les personnages de Léonora Miano demeurent, en effet, dans une logique dénominative qui relève de l'afropéanisme. Ils sont tous désignés, au premier abord, par des prénoms, et non par des

\footnotetext{
${ }^{4}$ Le camfranglais est un argot camerounais à base de français, d'anglais et de langues camerounaises.
} 
patronymes: Amok, Shrapnel, Amandla, Aligossi. Ces prénoms ressortissent de sphères culturelles autres que celles dont ils sont originaires. Ceux d'entre eux, comme les Frères atoniens, qui s'efforcent à un re-baptême s'inspirent de prénoms issus de l'Égypte antique, comme pour en appeler à un métissage de toutes les cultures afric aines: Khéry, Namer, Mayhem, etc.

L'extranéité consacrée dans la désignation des personnages et l'absence remarquable de patronymes sont porteuses de sens, puisqu'il s'agit, pour l'écrivaine, sinon de les voir rompre avec leur culture atavique, du moins de les fondre dans une culture autre dont le caractère hybride reflète leur afropéanité. Ainsi les personnages principaux du roman sont-ils désignés par des prénoms qui s'écartent de leurs origines.

Introduit dans la langue française vers 1830, le terme " amok " provient du malais "amuk" qui signifie "rage incontrôlable ". "l désigne un comportement meurtrier, toujours individuel, qui prend fin par la mise à mort de l'individu après que ce dernier a lui-même atteint un nombre plus ou moins considérable de personnes. Dans le roman, le personnage qui porte ce nom est d'origine camerounaise. Sans être physiquement violent, ce personnage, par son désir d'effacer toute trace de sa filiation, par son opposition à la lutte raciale menée par les Noirs et son refus de devenir père, finit par s'autodétruire : d'où sa disparition soudaine du récit.

Quant à Shrapnel, l'ami d'Amok, il porte le nom du général anglais inventeur d'un obus ainsi dénommé. Comme cette arme anti-personnel dont l'explosion projette des fragments de balles pour mettre hors d'état de combattre les personnes, la vie de Shrapnel vole en éclats. La mort semble le poursuivre dès la naissance : décès de sa mère à la naissance, mort de la grand-mère qui s'occupe de son éducation, destruction de l'arbre tutélaire, fin d'un monde traditionnel et disparition des ancrages de son clan (57-61). II finit par décéder de façon subite dans le métro (295).

Amandla, la Caribéenne, porte un nom qui renvoie en zulu et en xhosa ${ }^{5}$ au terme "pouvoir ». II s'agit d'un cri de ralliement populaire utilisé par l'African National Congress (ANC) au moment de la lutte contre l'apartheid. "Vivant dans un monde d'entre-deux, Amandla habite une peau ni noire ni blanche, porte un nom de famille qui tait ses origines, sur une terre qui n'est ni le Nord ni le Continent et à côté d'une mère qui se construit son propre monde" (Brussosa, 2013: 148). Sa mère, Victorine, qui est à l'origine de sa désignation par ce prénom, change elle-même le sien pour devenir Aligossi, nom qui renvoie à l'un des corps des Amazones du Dahomey, chargé de la protection du palais royal.

Par le jeu et le choc des langues et des musiques d'horizons culturels divers et par I'hétérogénéité du système de désignation des personnages, Tels des astres éteints de Léonora Miano apparaît finalement comme un véritable laboratoire de production et d'exposition de l'afropéanisme. À travers un paysage d'identités transmigrantes ni africaines ni européennes ni américaines, mais les trois à la fois parce que conçues dans un certain esprit "trinitaire ", Léonora Miano permet de découvrir un univers afropéen caractéristique du métissage ou de l'hybridation

\footnotetext{
5 Peuples de l'Afrique du Sud.
} 
culturelle des Noirs nés en Afrique ou d'origine africaine qui vivent désormais loin de la terre mère.

\section{Conclusion}

Notion popularisée dans l'espace francophone par l'écrivaine camerounaise Léonora Miano, l'afropéanisme se présente aujourd'hui comme la désignation d'une identité émergente qui prend de l'ascendant. L'afropéanisme, cette expérience noire et blanche dans un monde racialisé, concerne, de fait, de nombreuses personnes, africaines ou d'origine africaine, immigrées ou fils d'immigrés, nées en Europe ou y ayant grandi, et qui, bien que de couleur noire, possèdent l'une des nationalités européennes. De culture africaine-européenne, donc afropéenne, elles se situent dans un entre-deux identitaire, matérialisation effective d'une certaine transmigration des identités.

Dans Tels des astres éteints, Miano définit ainsi les contours de cette transmigration des identités à travers des personnages afropéens qui apparaissent dès lors comme des êtres culturellement hybrides par le brassage linguistique caractéristique de leurs expressions et par leurs goûts musicaux qui assemblent des airs africains, européens et américains. Leurs dénominations les inscrivent, par ailleurs, dans cette logique de métissage culturel puisqu'ils ne portent que des prénoms qui ressortissent de sphères culturelles autres que celles dont ils sont originaires. Par ce jeu d'écriture, Tels des astres éteints de Léonora Miano s'affiche, en définitive, comme une scription rhématique de la transmigration des identités.

\section{Bibliographie}

BAUDOIN, B. (2014) : La transmigration des âmes - Le phénomène walk-in. Paris: Trajectoire.

BILOA, E. (2007) : Le français des romanciers négro-africains-Appropriation, variationnisme, multilinguisme et normes. Paris : L'Harmattan.

BRUSSOSA, M-M. (2013) : "Tels des astres éteints de Léonora Miano : habiter un nom, habiter une peau ॥. Monografias de Çédille, 3, revista de estudios franceses, p. 143-155. Disponible sur http://cedille.webs.ull.es/M3/9-mallart.pdf. [Consulté le 17/08/2016].

CALVET, L-J. (1993) : La sociolinguistique. Paris : P.U.F.

CHALAYE, S. (2014) : «Pour une culture de marcottage ». Africultures, 99-100, p.16-21.

DEPESTRE, R. (1965) : «Réponse à Aimé Césaire ». Présence africaine, 4, p. 42-52.

DOMINIC, T. (2014): "Afropéanisme et littérature francophone subsaharienne: comment peut-on avoir un visage noir et être européen ? I). Africultures, 99-100, p. 92-103.

DUBOIS, J. et al. (2001) : Dictionnaire de linguistique. Paris : Larousse.

FAURE, S. (9 avril 2015) : «Chronique au mot - Afropéen (adj.) : qualifie le fait d'être noir et né en France 1 . Libération. Disponible sur http://www.liberation.fr/debats/\%202015/04/09/afropeen-adj-qualifie-le-fait-detre-noir-et-ne-en-europe 1237052 [Consulté le 25 mars 2017].

FANON, F. (1952) : Peau noire, masque blanc. Paris : Seuil. 
HÉLUIN, A. (12 décembre 2016) : "Massilia Afropéa : l'autre rencontre des cultures africaine et européenne ॥. Le Point. Disponible sur http://www.lepoint.fr.afrique. [Consulté le 27 avril 2017].

- (11 novembre 2016): «Eva Doumbia: il y a urgence à développer l'espace afropéen ». Le Point. Disponible sur http://www.lepoint.fr.afrique. [Consulté le 27 avril 2017].

LARANGÉ, D. (2014) : De l'écriture africaine à la présence afropéenne : pour une exploration de nouvelles terres littéraires. Paris: L'Harmattan.

LEFILLEUIL, A. (2014) : « Afropéanisme, identités frontalières et afropolitanisme : penser les nouvelles circulations 11 . Africultures, 99-100, p. 84-91.

MAALOUF, A. (1998) : Les Identités meurtrières. Paris : Grasset.

MAKHLOUF, G. (mai 2017): "J'écris dans l'écho des cultures qui m'habitent". L'Orient littéraire. Supplément mensuel de L'Orient Le jour, 131.

MIANO, L. (2012) : Habiter la frontière. Paris : L'Arche Éditeur.

- (2008) : Tels des astres éteints. Paris : Plon.

MIZOUNI, S. (2014) : "Léonora Miano et espace afropéen : territoire physique, site virtuel et identités dans Blues pour Élise \%. L'œuvre romanesque de Léonora Miano. A. D. TANG (ed.). Paris : L'Harmattan, p. 305-322.

TANG, A. D. (2014) : "Le sens du clair-obscur dans les romans de Léonora Miano ». L'œuvre romanesque de Léonora Miano. A. D. TANG (ed.). Paris : L'Harmattan, P. 67-80

VERMEREN, P. (2014) : «Identité nationale : une approche philosophique de la notion afropéa ». Africultures, 99-100, p. 66-75. 